\title{
Patterns of decerebration in infants and children : defects in homeostasis and sequelae
}

\author{
J. K. BROWN, T. T. S. INGRAM, AND S. S. SESHIA \\ From the Department of Child Life and Health, University of Edinburgh, \\ The Simpson Memorial Maternity Pavilion, and the Royal Hospital for Sick Children, Edinburgh
}

SUMMARY Sixty-four infants and children showing signs of decerebrate rigidity admitted to a paediatric unit have been studied. Cases of head injury, myelomeningocoele, and tumours were excluded from the series. The aetiological factors causing decerebration in the remainder fell into four main groups: infections, hypoxia, metabolic disease, and intracranial haemorrhage. Increased intracranial pressure was diagnosed in $87 \%$. Defects in homeostasis occurred in $75 \%$, respiratory abnormalities were present in $66 \%$, cardiovascular in $33 \%$, hypothermia in $30 \%$, and hyponatraemia in $17 \%$. Early recognition and treatment of raised intracranial pressure and defects in homeostasis are of the utmost importance if morbidity and mortality are to be minimized. There was a $31 \%$ mortality from the acute illness: $30 \%$ of the survivors were normal at follow-up examination; the remainder showed varying degrees of handicap. The severity of decerebration showed no correlation with aetiology or prognosis. The study shows that a wide range of disorders can lead to the clinical picture of decerebration in the young child, and that the prognosis is probably much better than in adults showing the same symptoms and signs.

Severe brain damage may occur in the course of many metabolic and infectious diseases affecting the brain in infants and young children in whom the acute stage of brain injury may be manifest clinically as convulsions, coma, and states of decerebrate and decorticate rigidity (generalized extensor hypertonus). In this paper the clinical findings of 64 children who showed a clinical picture of acute decerebration are described. The need for wider appreciation of the significance of acute decerebration and its emergency medical treatment is emphasized.

\section{DEFINITION}

Two major patterns of generalized extensor hypertonus in the human as a result of lesions of the brain have been described. In both there is generalized extension of the trunk, and of the lower limbs, which are thrown into a position of extension and internal rotation of the hips, extension of the knees, and plantar flexion of the feet, often with 'scissoring'. There is a gross increase of muscular tone, associated with exaggerated stretch reflexes and extensor plantar responses. No matter in which position the child is placed the increase of muscle tone and abnormalities of posture persist (Sherrington, 1898; Kinnier Wilson, 1920; Walshe, 1923a, b; Fulton, 1943).

In the first and commoner type which may be termed, after Sherrington, 'true decerebration' extensor rigidity in the legs is associated with adduction and internal rotation of the shoulders, extension of the elbows, pronation of the forearms with flexion of the wrists and digits, the thumb often being held beneath the fingers in the palms of the hands. In the second type, termed more accurately by Sherrington, 'decortication', there is semi-flexion adduction and internal rotation at the shoulders, semi-flexion or flexion of the elbows with flexion of the wrists and digits, the thumbs again being held beneath the flexed fingers as in the first type. For the sake of simplicity we shall refer to both these types of acute extensor hypertonus as 'acute decerebration' in this article.

In decerebrate rigidity of both types there is an exaggeration of the so-called 'primitive reflexes' including the rooting, lip, and sucking responses 
(Peiper, 1964). The grasp reflexes, the symmetrical and asymmetrical tonic neck reflexes, and the trunk incurvation reflex are easily elicited.

There is a marked similarity in the postures assumed by decerebrate babies and babies in the dystonic stages of diplegia and dyskinetic cerebral palsy, but in the latter changes of the position of the child in space tend to modify the child's posture and muscle tone (Ingram, 1964).

\section{METHODS}

Sixty-four patients were studied between 1968 and 1970. The majority of patients were seen in the general medical and surgical wards in the Royal Hospital for Sick Children, Edinburgh, and in the nurseries of the Simpson Memorial Maternity Pavilion, Royal Infirmary, Edinburgh, as soon as they showed neurological abnormalities. Thereafter they were seen frequently while in hospital. The survivors were examined regularly as outpatients. Twenty of the 64 patients died between 24 hours and nine months after the initial illness. Of these, 13 came to necropsy.

Patients suffering from the following categories of neurological disease who showed decerebrate rigidity were excluded from consideration: known head injuries; intracranial tumours; spina bifida with or without hydrocephalus; mild transient neonatal decerebration of the type which commonly follows hypoxia; apparent decerebration in the newborn the result of hypocalcaemia and/or hypomagnesaemia (Brown, 1970). Neonates with persistent decerebration of more than 24 hours duration after birth or postnatal hypoxia, were included.

\section{RESULTS}

AGE RANGE The ages of the patients studied varied from 1 day to 10 years. Sixty of the 64 patients were aged less than 4 years (Table 1).

TABLE 1

AGE AND SEX DISTRIBUTION OF CASES

\begin{tabular}{cccc}
\hline Age $(y r)$ & Ma!e & Fcmale & Total \\
\hline Under 6/12 & 24 & 12 & 36 \\
1 & 3 & 2 & 5 \\
2 & 3 & 1 & 4 \\
3 & 3 & 5 & 8 \\
4 & 4 & 3 & 7 \\
Over 4 & 4 & 0 & 4 \\
\hline
\end{tabular}

SEX RATIO There were 41 boys and 23 girls, a ratio of almost two to one.

PREVIOUS HISTORY We tried to determine if there were any indication of abnormality before the illness in which the episode of decerebration had occurred. There was strong presumptive evidence in 53 cases $(83 \%)$ that the children had been normal. Three were known to have shown neurological symptoms and/or signs previously, and in the remaining eight the earlier histories were too short or too inadequate for any reliable opinion to be made as to the child's previous normality or abnormality.

CLASSIFICATION OF PATIENTS Decerebrate rigidity is almost always the result of severe, and usually acute, raised intracranial pressure $(87 \%)$, metabolic disturbance $(5 \%)$, or diffuse encephalopathic disease $(8 \%)$, however these are caused. In a significant proportion of the patients suffering from raised intracranial pressure, cerebral oedema was thought to be the cause $(51 \%)$, while hydrocephalus and space occupation accounted for equal numbers of the remainder.

It will be seen (Table 2) that a large number of underlying disorders may result in the clinical picture of decerebrate rigidity. Moreover, a number of these may produce decerebration in different ways (Table 2).

\section{CLINICAL OBSERVATIONS}

PREMONITORY SIGNS AND ONSET OF DECEREBRATE RIGIDITY A number of typical neurological changes may occur in young children shortly before decerebrate rigidity appears-for example, neck retraction, strabismus, and lessening of awareness. Cycling movements of the lower limbs, which are occasionally unilateral, are common premonitory signs. 'Doggy paddling' movements in the arms are the equivalent in the upper limbs of the cycling movements in the legs, but are less commonly seen.

At this stage it is common to find that there is an exaggeration of the symmetrical and asymmetrical tonic neck reflexes, the Perez reflex (extension of the spine, flexion of the legs, and 
TABLE 2

AETIOLOGY OF DECEREBRATE RIGIDITY IN 64 CHILDREN

\begin{tabular}{|c|c|}
\hline & $\begin{array}{l}\text { Cases } \\
\text { (no.) }\end{array}$ \\
\hline \multicolumn{2}{|l|}{ Intracranial haemorrhage $(30 \%)$} \\
\hline $\begin{array}{c}\text { Subdural haemorrhage-battered baby } \\
\text { —other causes }\end{array}$ & $\begin{array}{l}5 \\
5\end{array}$ \\
\hline Intraventricular haemorrhage & 6 \\
\hline Arteriovenous malformation & 1 \\
\hline Other & 2 \\
\hline \multicolumn{2}{|l|}{ Infections $(30 \%)$} \\
\hline Meningitis & 8 \\
\hline Encephalitis & 6 \\
\hline Abscess & 1 \\
\hline Cortical thrombophlebitis & $i^{*}$ \\
\hline Septicaemia (with intravascular coag.) & 2 \\
\hline Fatty liver encephalopathy & 1 \\
\hline \multicolumn{2}{|l|}{ Hypoxia $(18 \%)$} \\
\hline Cardiac arrest (anaesthetic) & 3 \\
\hline Neonatal hypoxia & 6 \\
\hline Drowning & 1 \\
\hline Post convulsion & 2 \\
\hline \multicolumn{2}{|l|}{ Metabolic $(14 \%)$} \\
\hline Hypernatraemic dehydration (G. ent.) & 3 \\
\hline Alkalotic tetany & 2 \\
\hline Kernicterus & 1 \\
\hline Burns encephalopathy & 2 \\
\hline Water intoxication (transfusion) & 1 \\
\hline \multicolumn{2}{|l|}{ Other $(8 \%)$} \\
\hline Birth trauma & 3 \\
\hline Congenital malformation & 1 \\
\hline Sagittal sinus injury & i \\
\hline
\end{tabular}

* Plus two in meningitic group.

extension of the head on pressure stimulation over the dorsal spinous processes), and the trunk incurvation response. These features should be regarded as danger signals, for they are often rapidly followed in a matter of minutes, or at most in one to two hours, by the appearance of decerebrate rigidity in a high proportion of patients.

Decerebrate rigidity is usually first evident in the lower limbs, which extend at the hips and knees with the feet plantar flexed, toes abducted, and great toes hyperextended as in the spontaneous extensor plantar response (spontaneous Babinski response). The pattern may then develop into one or other of the full pictures of decerebrate rigidity described above.

In some patients the first evidence of extensor hypertonus occurs in the neck and proceeds in a cephalo-caudal direction, so that head retraction is closely followed by extension and hyper- tonus in the trunk and upper limbs and then in the lower limbs.

Once the picture of decerebrate rigidity is established, the Perez reflex, the trunk incurvation reflex, cycling movements, and the asymmetrical tonic neck reflexes are temporarily inhibited by the severe extensor rigidity of the muscles, but may reappear as soon as it lessens.

In the established picture of decerebrate rigidity a number of stimuli cause an increase in the extensor pattern and in muscle tone. These include exerting gentle pressure on the nose, which tends to cause increased hyperextension of the great toe (termed unofficially in our clinic the nasal Babinski response or snout reflex). Perineal stimulation may have a similar effect. Occasionally, the severity of the rigidity may be observed to vary during the respiratory cycle, becoming more marked on inspiration, and lessening on expiration.

SEVERITY OF DECEREBRATE RIGIDITY It is possible to recognize varying degrees of severity in decerebrate rigidity. (1) The term 'mild decerebrate rigidity' is applied when the child shows neck retraction with exaggerated extensor reflexes and generalized rigidity only on stimulation such as handling. This rigidity does not alter with changes of position in space. (2) Moderately severe decerebrate rigidity is considered to exist when there is neck retraction with persistent extensor postures of the lower limbs. Alternatively, there may be neck retraction with involvement of the trunk and upper limbs, the lower limbs being affected to a lesser extent. (3) Severe decerebrate rigidity is marked by opisthotonos with gross extension of the lower limbs and usually also the upper limbs, though there may be semi-flexion at the elbows as noted above (Fig. 1a, b, c).

In the present series of 64 patients, two were classified in the mild category (1), 17 in the moderate category (2), and 45 in the category termed severe (3). (cf. Appendix).

Neither the cause of the decerebration nor the prognosis can be determined on the basis of the severity of the decerebration. For example, in case 61 , water intoxication produced a picture of total decerebration, and in case 20 a large and ultimately fatal subdural haematoma produced only mild to moderate extensor hypertonus (Table 2). 


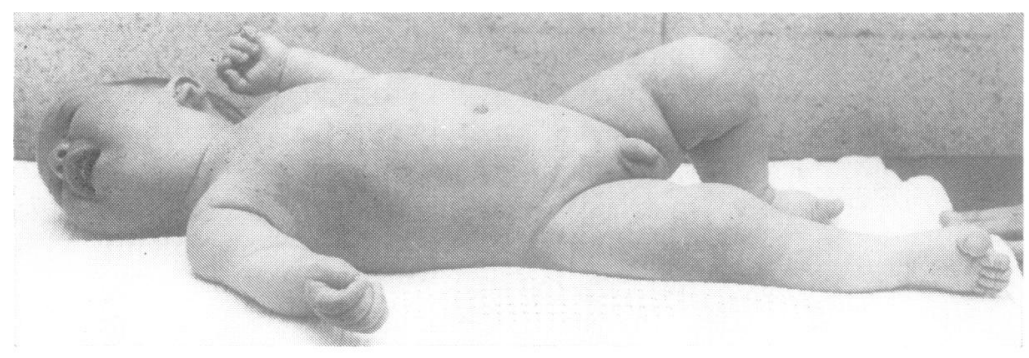

(a)

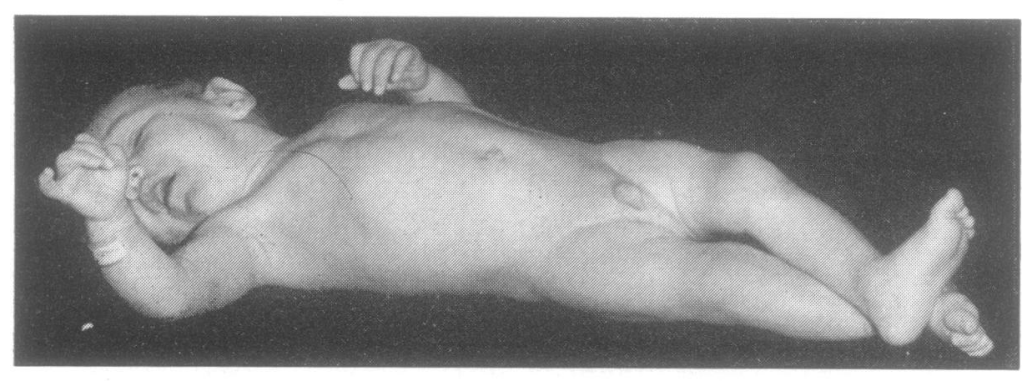

(b)

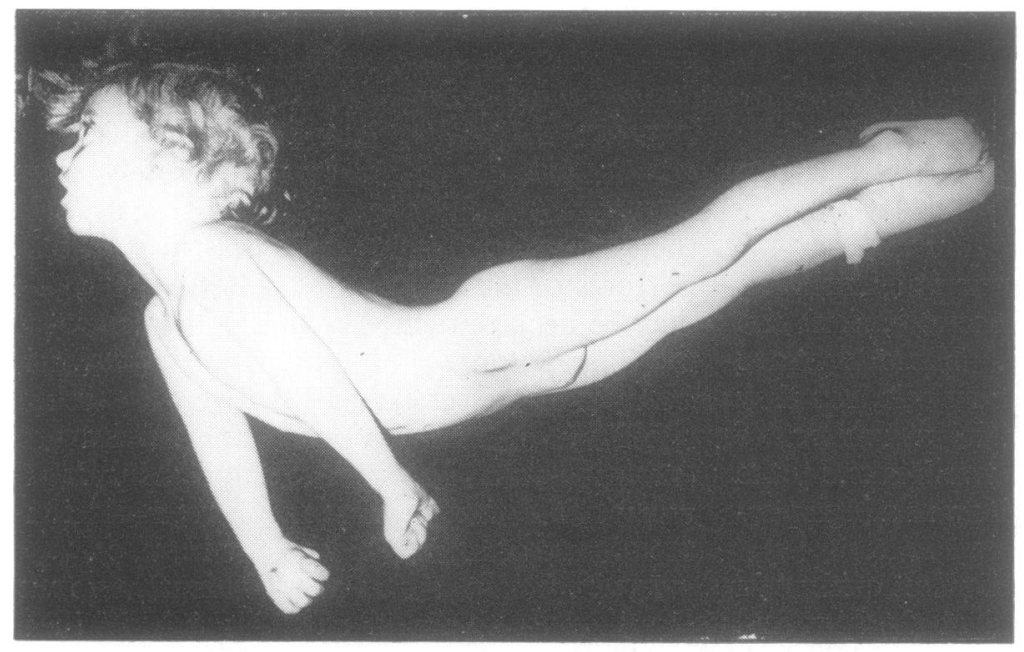

FIG. 1. Clinical pattern of extensor hypertonus.

(a, top) Mild. (b, centre) Moderate. (c, bottom) Severe.

AWARENESS AND IMPAIRMENT OF CONSCIOUSNESS It is difficult to assess the level of consciousness in young infants. Instead it is necessary to use criteria of alertness or level of arousal, as suggested by Prechtl and Beintema (1964). In older children, above the age of 6 months, depression of consciousness may be assessed approximately in the same way as adults. The stages marking the progressive depression of the level of consciousness are of particular value in such patients (Wylie and Churchill-Davidson, 1965).

It was found that most older children in the series showed depression of consciousness when intracranial pressure was significantly raised. In 
contrast, a number of the young infants lay in a totally opisthotonic posture and yet could suck a bottle and even smile at the appearance of their mothers. The level of alertness and arousal was thought to be normal in 10 infants. Sixteen infants were classified as being extremely apathetic, a stage which was considered to be the equivalent of being unconscious in the older child. Six children showed impairment of consciousness and 32 were unconscious, using the criteria suggested above. There was a striking dissociation in some patients between the severe degree of decerebrate rigidity and the level of consciousness (Halsey and Downie, 1966).

SIGNS OF INCREASED INTRACRANIAL PRESSURE A high proportion of patients had signs of raised intracranial pressure. This was diagnosed either on the basis of abnormalities of the fundi or changes in the pupils and eye movements as

TABLE 3

OCULAR FINDINGS ASSOCIATED WITH ACUTE DECEREBRATION IN INFANTS AND CHILDREN

\begin{tabular}{|c|c|c|}
\hline & \multicolumn{2}{|r|}{ Cases } \\
\hline & (no.) & $(\%)$ \\
\hline \multicolumn{3}{|l|}{ Fundi } \\
\hline Normal & 32 & 50 \\
\hline Papilloedema & 24 & $37 \cdot 5$ \\
\hline Retinal haemorrhage & 10 & $15 \cdot 6$ \\
\hline \multicolumn{3}{|l|}{ Pupils } \\
\hline Normal & 32 & 50 \\
\hline Unequal & 5 & $7 \cdot 8$ \\
\hline Pinpoint & 7 & 11 \\
\hline Dilated & 20 & 31 \\
\hline \multicolumn{3}{|l|}{ Ocular movements } \\
\hline Normal & 22 & $34 \cdot 4$ \\
\hline 'Sunset' sign & 6 & $9 \cdot 4$ \\
\hline Ophthalmoplegia & 13 & 20 \\
\hline Doll's eye response & 14 & $21 \cdot 9$ \\
\hline VI nerve palsy (isolated) & 2 & 3 \\
\hline Conjugate spasm & 7 & $\begin{array}{c}11 \\
\text { (vertical 2) }\end{array}$ \\
\hline
\end{tabular}

listed in Table 3, or because the sutures were splayed, the fontanelle tense, or the occipitofrontal circumference was increasing. The latter signs were present in 28 patients $(44 \%$ of the series).

It will be noted from Table 3 that papill- oedema was present in only 24 of the 56 children with eye signs suggesting the presence of raised intracranial pressure, and was absent in $57 \%$. Severe cerebral oedema, confirmed at necropsy, was found to be compatible with normal fundal appearances. Decerebration due to diffuse encephalopathic lesions or metabolic causes was always associated with normal fundal appearances and usually also with normal pupils, though abnormal eye movements were found in some patients in all three of the major categories (Table 3).

SEIZURES Seizures occurred in $42(64 \%)$ of the patients in the series during the illness associated with the appearance of decerebrate rigidity. The seizures were focal in $21(32 \%)$, of grand mal type (or of the generalized type seen in infancy), in 17 patients $(26 \%)$, and essentially tonic in type in $13(20 \%)$. Nine patients had seizures of more than one type.

ABNORMALITIES OF RESPIRATION Forty-three patients $(66 \%)$ showed abnormalities of respiration while in the state of decerebrate rigidity. In two patients (cases 44,45 ) the respiratory disorder was considered to be the primary cause of brain dysfunction (see below), but in the other 41 there was no evidence of primary respiratory disease and the abnormalities of respiratory function were considered to be of neurogenic origin.

One infant (case 44) who suffered from an $E$. coli septicaemia, required intermittent positive pressure respiration. The hyperventilation which resulted reduced his plasma $\mathrm{CO}_{2}$ to $25 \mathrm{mmHg}$ with an acute alkalosis and he showed a picture of complete decerebration with opisthotonos and generalized fits of the multifocal infantile type. Adjustment of the ventilator completely reversed the clinical picture. The baby ceased to convulse and the decerebrate rigidity disappeared. Another infant was hyperventilated during bronchoscopy. He showed a picture of decerebrate rigidity which lasted for some hours, though recovery was complete (case 45 ).

The respiratory abnormalities which were encountered in association with decerebrate rigidity are shown in Table 4.

ABNORMALITIES OF CARDIOVASCULAR FUNCTION Bradycardia, irregularity of the heart rate and 
TABLE 4

RESPIRATORY ABNORMALITIES IN INFANTS AND CHILDREN WITH ACUTE DECEREBRATION

\begin{tabular}{lrr}
\hline & \multicolumn{2}{c}{ Cases } \\
\cline { 2 - 3 } & $($ no. $)$ & $(\%)$ \\
\hline Cyanotic attacks or cyanosis & 14 & 21 \\
Apnoeic attacks or respiratory arrest & 21 & 32 \\
Tachypnoea (over 70/min) & 8 & 12 \\
Bradypnoea & 6 & 9 \\
Cheyne-Stokes respiration & 3 & 5 \\
Laryngeal stridor & 5 & 8 \\
\hline
\end{tabular}

cardiac arrest, all known to result from raised intracranial pressure, were encountered in a number of patients. Bradycardia was found in six (cases 1, 8, 9, 11, 13, 35), though in one case (case 9) the rate slowed markedly to 20 per minute. In contrast, tachycardia of more than 200 per minute was noted in six patients and in another five the heart rate was between 170 and 200 per minute.

The electrocardiogram (ECG) may be abnormal with sinus bradycardia, sinus arrest or varying heart block and yet it may revert dramatically back to normal if the intracranial pressure is reduced, as by aspirating the lateral ventricle through the anterior fontanelle.

One child (case 9), who also showed bradycardia, had five episodes of cardiac arrest which were associated with other evidence of autonomic over-activity-intense salivation, sweating, and borborygmi which were audible without a stethoscope. Injection of atropine intravenously immediately reversed the cardiovascular ab-

TABLE 5

DEFECTS IN HOMEOSTASIS ASSOCIATED WITH ACUTE DECEREBRATION IN INFANTS AND CHILDREN

\begin{tabular}{lrr}
\hline \multicolumn{1}{c}{ Defect } & \multicolumn{2}{c}{ Cases } \\
\cline { 2 - 3 } & $($ no. $)$ & $(\%)$ \\
\hline Hypothermia: temperature $35^{\circ} \mathrm{C}\left(95^{\circ} \mathrm{F}\right)$ or less & 19 & $29 \cdot 7$ \\
Hyperthermia: temperature $40^{\circ} \mathrm{C}\left(104^{\circ} \mathrm{F}\right)$ or over & 7 & 10.5 \\
Hyponatraemia: sodium $130 \mathrm{~m}$-equiv/1. or less & 11 & 17 \\
$\quad$ lowest $110 \mathrm{~m}-$ equiv/1. & 6 & $9 \cdot 4$ \\
Hypoglycaemia & 2 & 3 \\
Hyperglycaemia: over $200 \mathrm{mg} / 100 \mathrm{ml}$. & 2 & 3 \\
Failure to thrive: ?diencephalic syndrome & & \\
\hline
\end{tabular}

normalities. Six other patients (cases 1, 5, 7, 13, $14,17)$ suffered from cardiac arrest, apparently secondary to an increase of intracranial tension, associated with decerebrate rigidity. In another three, cardiac arrest occurred during anaesthesia in previously healthy children. In two (cases 9 and 13) of the 10 patients who suffered from episodes of cardiac arrest, the heart stopped beating on more than one occasion. Two of the children who suffered from cardiac arrest, apparently as a result of raised intracranial pressure (cases 13 and 62) associated with hydrocephalus, showed no significant change in their neurological findings on later examination.

TABLE 6

SEQUELAE OF ACUTE DECEREBRATION IN INFANTS AND CHILDREN

\begin{tabular}{lcc}
\hline \multicolumn{1}{c}{ Sequelae } & \multicolumn{2}{c}{ Cases } \\
\cline { 2 - 3 } & $(n o)$. & $(\%)$ \\
\hline Dead & 20 & 31 \\
Normal & 19 & $29 \cdot 5$ \\
Severe handicap & 16 & 24 \\
Mental retardation & 15 & \\
Blind & 2 & \\
Deaf & 1 & \\
Epileptic & 5 & \\
Tetraplegic or dystonic & 10 & \\
Hemiplegia & 6 & \\
Mild handicap & 7 & $11 \cdot 5$ \\
Ataxia & 5 & \\
Hyperkinesis & 3 & \\
Mild hemiparesis & 1 & \\
Abnormal before acute episode (no change) & 2 & 3 \\
\hline
\end{tabular}

TEMPERATURE REGULATION Some other defects in homeostasis are summarized in Table 5. Hypothermia, defined as a rectal temperature of $35^{\circ} \mathrm{C}\left(95^{\circ} \mathrm{F}\right)$ or less, was present in 19 cases $(30 \%)$ during their acute illnesses. A temperature of $40^{\circ} \mathrm{C}\left(104^{\circ} \mathrm{F}\right)$ or more was noted in seven patients, and in one (case 1) the temperature was $41 \cdot 7^{\circ} \mathrm{C}\left(107^{\circ} \mathrm{F}\right)$.

Marked fluctuations in temperature as wide as $29^{\circ}-41 \cdot 7^{\circ} \mathrm{C}\left(85^{\circ}-107^{\circ} \mathrm{F}\right)$ were seen in one 24 hour period. In two patients loss of temperature control persisted-in case 31 for a period of eight months until he died, and in the other case, who suffered from permanent neurological damage after his episode of decerebration, it was present one year later (case 12) (Fig. 2). 


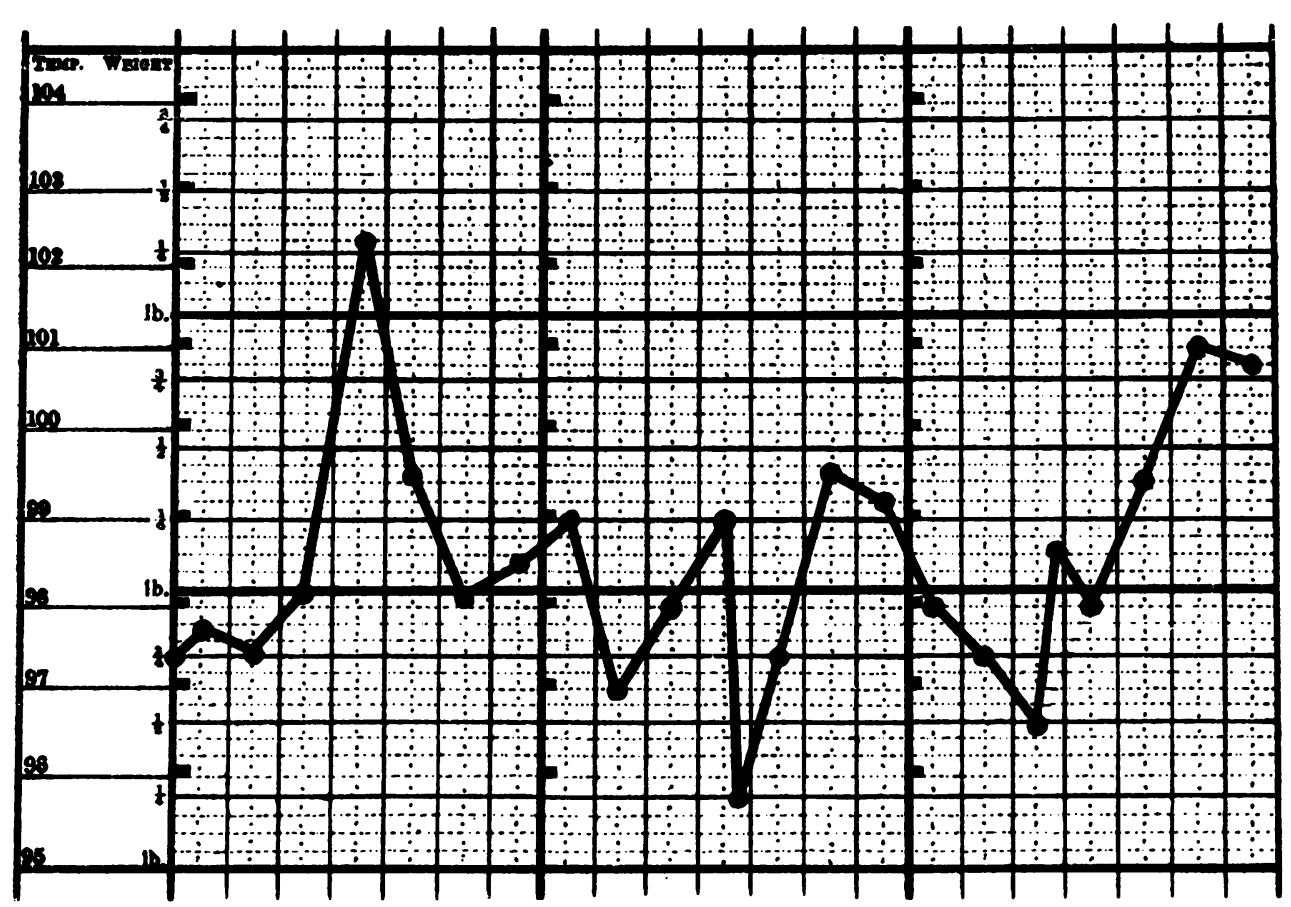

FIG. 2. Loss of temperature control with poikilothermia in an infant after severe asphyxial brain damage, associated with decerebration.

CEREBROSPINAL FLUID In $78 \%$ of patients a lumbar puncture was performed, because the risk of missing the presence of meningitis was considered to be greater than that of causing coning of the brain, even when there was evidence of increased intracranial pressure. Intravenous mannitol (5-7 ml./kg) was given 20 minutes before the lumbar puncture in order to lessen the dangers of the procedure, but in spite of this the clinical conditions of three patients deteriorated after the puncture.

ELECTROLYTES AND OSMOLALITY Hyponatraemia was considered to be present when the serum sodium concentration was $130 \mathrm{~m}$-equiv/l. or less. This was found in 11 patients $(17 \%)$ and in two it was only 110 m-equiv/l. (cases 26 and 64).

Water intoxication is one cause of cerebral oedema and in case 60 the administration of dextrose solution produced the syndrome, the serum osmolality falling acutely to $256 \mathrm{~m}$-osmol/ $\mathrm{kg}$ (the normal range being 280-295 m-osmol/ $\mathrm{kg})$. The osmolality was rapidly restored to normal by the infusion of saline and the child's decerebration disappeared.

The fact that control of osmolality may be impaired in severe brain damage was illustrated by an infant (case 21) who was admitted to hospital suffering from Haemophilus influenzae meningitis. He was treated with antibiotics from the time of admission, but 24 hours later he started to have convulsions and developed severe decerebrate rigidity with tachycardia of over 200 per minute, bilateral papilloedema, and fixed dilated pupils. The serum osmolality was found to be low at $255 \mathrm{~m}$-osmol/ $\mathrm{kg}$ and the osmolality of the urine high at $578 \mathrm{~m}$-osmol $/ \mathrm{kg}$. It was felt that the child had cerebral oedema due to water intoxication probably due to inappropriate secretion of antidiuretic hormone. $\mathrm{He}$ was treated by the infusion of hypertonic saline $(10 \%)$ and dexamethasone. This therapy resulted in cessation of the fits, the disappearance of decerebration, and resolution of the papilloedema. On subsequent follow-up examination the child was found to be neurologically normal. 
In three other patients too rapid correction of hypernatraemia by intravenous fluid was thought to be responsible for brain swelling accompanied by decerebrate rigidity.

CONTROL OF BLOOD SUGAR Hypoglycaemia (defined from term onwards as a blood glucose of less than $30 \mathrm{mg} / 100 \mathrm{ml}$.) was present in six patients, in one of whom the blood glucose was found to be only $5 \mathrm{mg} / 100 \mathrm{ml}$. Hyperglycaemia, defined as a blood glucose level of $200 \mathrm{mg} / 100 \mathrm{ml}$. or more, was noted in two other patients (cases 3 and 43).

\section{TREATMENT}

The patients were given many different treatments during the study because of the many different causes of decerebration and associated abnormalities. Vagal over-activity manifest as cardiac irregularity, bradycardia, or cardiac arrest was corrected by the administration of atropine in two cases (cases 9 and 13), but might have been considered in others. Hypertonic saline was administered in two patients who showed hypo-osmolality. Glucose was given intravenously for the correction of hypoglycaemia in six patients. Attempts to aspirate subdural haematomata through the lateral angles of the anterior fontanelle were made in 14 patients. Raised intracranial pressure associated with hydrocephalus was lowered by removal of cerebrospinal fluid from the lateral ventricle by ventricular tap in 13 patients. Cerebral oedema was treated by a combination of mannitol $20 \%$, 5-7 ml./kg (16 cases), and dexamethasone given parenterally in 30 cases. In newborn infants dexamethasone alone was used. It is our practice to nurse these patients in the sitting position providing an adequate airway can be maintained. Neurosurgical intervention was needed in 15 cases $(20 \%)$.

FOLLOW-UP STUDIES All the surviving patients were seen as outpatients after they had been discharged from hospital. Twenty children $(31 \%)$ had died during their acute illness and $19(30 \%)$ were considered to be completely healthy, normal children on later follow-up. Two patients were known to have had evidence of neurological handicap before their acute episode. Their neurological findings were not altered on subse- quent follow-up examination, although one of them had suffered cardiac arrest during the acute episode (case 13). Seven children (11.5\%) were found to manifest ataxia, hyperkinetic behaviour disturbances, mild hemiparesis, or paralytic squints. Sixteen of the patients $(24 \%)$ showed severe mental and physical handicaps, usually associated with a tetraplegic type of cerebral palsy (Table 6).

Forty-one children suffered from epileptic seizures when acutely ill; in only five did fits occur afterwards.

PATHOLOGICAL FINDINGS Necropsy was carried out in 13 of the 20 patients who died. Many different pathological abnormalities were found. Unequal swelling of the hemispheres had caused shifts of the brain across the midline; shifts downwards were found with tentorial herniation; lateral compression of the brain-stem and infarction of the occipital lobes due to compression of a posterior cerebral artery and coning at the foramen magnum were all seen. In one patient necrosis of the herniated cerebellar tonsils re- $\stackrel{\vec{\Phi}}{\circ}$ sulted in cerebellar tissue being found in the lumbar theca. Hydrocephalus, subdural haematoma, and encephalitis were confirmed in응 patients in whom this had been the provisional $\overrightarrow{0} \cdot \overrightarrow{0}$ antemortem diagnosis. In three infants the $\omega$ brain was found to be softened, pale, swollen, and almost liquid, so marked was the cerebral infarction.

\section{DISCUSSION}

Sherrington found that after a section of the brain at an intercollicular level there was rigidity in the trunk or all four limbs, with extension of the neck and trunk, adduction and internal rotation of the shoulders, extension of the elbows, pronation of the forearms, flexion of the wrists and fingers-usually over the adducted thumbs-adduction and internal rotation of the hips, extension of the knees, and plantar flexion of the feet so that 'scissoring' of the lower limbs frequently occurred (Sherrington, 1906, 1947). This type of rigidity has been attributed to release of the activity of alpha nerve fibres which control muscle tone in experimental animals, though interpretation is more difficult in the 
human (Rushworth, 1964). The second type of decerebrate rigidity described by Denny-Brown (1966) in which there is flexion at the shoulders and elbows so that the upper limbs tend to be held across the chest tends to occur when lesions of the brain are more diffuse in nature, and particularly when the basal ganglia and cerebellum are involved. In animals it has been attributed to the release predominantly of the gamma efferent system in the spinal cord.

The clinical pictures of the two types of decerebrate rigidity are usually quite distinct, but the explanation as to why one or other should occur is impossible to make in terms of presumed underlying pathological change in the brain (Denny-Brown, 1962). Both types may be abolished by deep anaesthesia and the posture and rigidity of the limbs are altered in the gamma type if they are de-afferented. A number of authors have considered that the brain-stem is more often damaged in patients in whom the upper limbs show flexor patterns (Walshe, 1923a; Granit, 1955; Denny-Brown, 1962).

The two types of decerebrate rigidity described must be distinguished from other states in which there is extension or hyperextension of the neck and trunk, and extension of the limbs with rigid increase of tone. In some diseases of the corpus striatum, for example, transient or long-lasting posture of this type may be found-the so-called dystonic syndrome described by Denny-Brown (1963). In this syndrome posture is modifiable by changes of position and by alteration of the position of the limbs. Dystonic postures of this type are commonly found in the early stages of the development of dyskinetic or diplegic cerebral palsy in severely affected patients (Ingram, 1964). They may also be observed in the course of prenatal and early postnatal development, before higher cerebral control of motor function has developed.

Thus decerebrate and dystonic postures may be explained in developmental terms. By 12 weeks of gestation the foetus shows well-developed flexor tone with recoil and adduction and flexion of the limbs, if the corresponding dermatomes are stroked. This response appears to be predominantly spinal in origin. By the 18 th week of gestation flexor tone has become inhibited and extensor reflexes appear. The premature baby born at 28 weeks' gestation has a tendency to mass extension of the trunk, crossed extension of the limbs, trunk incurvation, and tonic neck reflexes. Almost any abrupt stimulation or change in position is liable to produce sudden rigid extension of the neck and trunk and of the limbs, especially the lower limbs with hyperextension of the great toes. Similar extensor patterns have been described in anencephalic infants and have been witnessed personally (Walshe, 1923a; Peiper, 1964).

Between 30 and 40 weeks of gestation there is again an increase in flexor tone, and by term the child's posture is one of semi-flexion of the neck, trunk, and limbs rather similar to that seen between 12 and 18 weeks. After the first month of extrauterine life another extensor phase occurs and reaches its maximum at the age of 12 to 16 weeks (Ingram, 1970). When babies at this stage of motor development are placed in the supine position supported by a hand beneath the back, the posture assumed may be very similar to that found in decerebrate rigidity or in the dystonic syndrome as described by Denny-Brown. It is important to distinguish babies who show a wellmarked, but physiological, stage of 'extensor tonus' from babies showing abnormalities of posture and tone attributable to brain disease.

As seen in Table 2 a wide variety of pathological conditions may be associated with decerebrate rigidity. The commonest of these is raised intracranial pressure with associated compression of the mid brain due to coning at the tentorial orifices (Johnson and Yates, 1956). This neuropathological state is most often caused by swelling of the brain secondary to head injury, tumours of the posterior fossa, or hydrocephalus.

Most of the other causes of decerebrate rigidity produce their effects by causing cerebral oedema and raised intracranial pressure. These are found in lead poisoning (Wechsler, 1963), diabetic ketoacidosis (Young and Bradley, 1967), hypernatraemic dehydration (Morris-Jones, 1967), and in cases of pseudo-tumour cerebri (Greer, 1967). Brain swelling can occur in young infants after very trivial trauma and minor hypoxic episodes. It may be associated with the use of certain drugs such as tetracyclines, steroid withdrawal, and vitamin intoxications. There is what appears to be a specific condition causing toxic encephalopathy associated with fatty degeneration of the liver, hypoglycaemia, and 
severe metabolic acidosis which occurs predominantly in young children under 5 years of age described by Reye, Morgan, and Baral (1963) and Simpson (1966). Minor scalds may be associated with severe brain oedema and decerebrate rigidity with loss of homeostasis in children under 5 years of age (there were two cases in the present series, nos. 1 and 2) (Emery and Reid, 1962).

The other causes of extensor hypertonus in the child which produce decerebrate postures include diffuse encephalopathic diseases of the mid brain which may occur in encephalitis, tumours, hypoxia or ischaemic lesions. Pure metabolic disturbances may also have a direct effect on the brain-stem causing release of decerebrate rigidity without any associated swelling. This is seen in severe kernicterus (Eastham and Jancar, 1968), maple syrup urine disease (Martin and Norman, 1967), hepatic failure (Conomy and Swash, 1968), hypocalcaemia, hypomagnesaemia (Brown, 1970), and in alkalosis or phenothiazine poisoning. Intracranial haemorrhage accounted for $30 \%$ of the present series. The battered baby suffering from intracranial haemorrhage is one of the diagnoses which must always be borne in mind in any infant who presents with unexplained extensor hypertonus.

HOMEOSTATIC CONTROL As indicated above, a breakdown in homeostatic control may be associated with decerebrate rigidity. Such an association may involve abnormalities of cardiorespiratory control, and regulation of osmolality, serum sodium, blood glucose, temperature, and $\mathrm{pH}$ in which it is presumed that the disturbance in homeostasis is secondary to the disease process which also results in extensor hypertonus. A possible mechanism would be the pressure effect on the hypothalamus of a swollen brain or of a dilated third ventricle in hydrocephalus. In decerebrate rigidity there is frequently an imbalance between the sympathetic and parasympathetic components of the autonomic nervous system and this may account for the pinpoint or fixed dilated pupils, the bradycardia or tachycardia, the hypo- or hyperglycaemia, the hypo- or hyperthermia, and the other autonomic disturbances often found (Robertson and Pollard, 1955; Appenzeller, 1970).

Abnormalities of the function of the autonomic nervous system on the circulation may cause hypotension or hypertension and this may be associated with pulmonary oedema (Chapman, Livingston, Livingston, and Sweet, 1950; Paine, Smith, and Howard, 1952; Hilton, 1966; Ducker, 1968). In young infants an odd syndrome of tachycardia, enlargement of the liver, and peripheral oedema may occur secondary to lesions of the brain and has been known as cerebral heart failure (Gray and Prosser, 1967).

Abnormalities of cardiac rate or rhythm and associated disorders of the circulation may be secondary to diseases of the nervous system and may also cause brain damage from ischaemia. Thirty-three per cent of the present series showed some abnormality of the cardiovascular system. There may be vagal stimulation with resultant bradycardia, sinus arrest or nodal escape, and typical changes in the ECG. Alternatively, severe? tachycardia (which may impair diastolic filling) can also be due to central sympathetic overactivity. Before bradycardia becomes apparent, $\subseteq$ there may be marked exaggeration of the normak sinus arrhythmia and irregularities of the pulseo may also be due to varying degrees of heart block. Changes in the ECG may occur after subs음 arachnoid haemorrhage when large T-waves, left bundle branch block, U-waves, and prolongation of the Q-T interval may be seen (Shuster, 1960; Srivastava, and Robson, 1964).

Respiratory difficulties were present in $66 \%$ of cases. Disorders of pulmonary ventilation may occur when either hyperventilation producing alkalosis and a reduction in cerebral flow (Plum and Swanson, 1959) or hypoventilation is present. Hypoventilation is more common and is associated with retention of carbon dioxide and acidosis. This is dangerous because the retention of carbon dioxide may cause cerebral venous dilatation, further increasing intracranial pressure. Apnoeic attacks or respiratory arrest were seen most often after a period of bradypnoea (McNealy and Plum, 1962). Tachypnoea, bradypnoea, Cheyne-Stokes, or gasping respirations all occurred. Between the two different phases of Cheyne-Stokes respiration, pupillary size, conjugate eye deviation, and plantar responses could all vary. Laryngeal stridor, 
recorded by a number of earlier workers, was found in five patients in the present series (Morley, 1969). The acid base status of the CSF was not studied in the present series of cases, but it is known that respiratory abnormality and encephalopathy may be associated with changes in CSF acid-base balance (Posner, Swanson, and Plum, 1965).

In view of the high incidence of respiratory disorders associated with decerebrate rigidity in the present series the adequacy of ventilation should be routinely monitored either as minute volume, end tidal $\mathrm{CO}_{2}$, or by sequential blood gas studies. The airway must at all times be kept patent. Early tracheotomy in children with decerebrate state has been recommended (Robertson and Pollard, 1955). This is not without hazard in small children and we found the use of Jackson Rees nasotracheal intubation satisfactory. There is no place for the use of respiratory stimulant drugs in these cases as they may precipitate status epilepticus. Intermittent positive pressure ventilation was required in $20 \%$ of cases in the present series because of ventilatory failure.

Temperature regulation depends on hypothalamic function and hypothalamic connections, regulation of secretion of thyrotropic hormone, skin blood flow, shivering and sweating, and an intact autonomic nervous system (Roddie, 1969). Three abnormalities may occur: hypothermia, hyperthermia, and poikilothermia. Hyperthermia has a recognized association with hyperglycaemia and pinpoint pupils in pontine lesions (Brain and Walton, 1969) but hypothermia is said to be more common in diseases of the central nervous system. In the present series, $30 \%$ of the cases had a temperature of $35^{\circ} \mathrm{C}\left(95^{\circ} \mathrm{F}\right)$ or less at some point in the acute stage of the disease. Hypothermia is important in the very small infant, as hypoglycaemia, acidosis, and an increase in oxygen consumption may all occur as a result.

The autonomic nervous system is involved in blood glucose control; the sympathetic component causes breakdown of the liver glycogen and inhibition of insulin release (Buchanan, 1969). Through the vagus nerve the parasympathetic nervous system stimulates insulin release (Levine and Haft, 1970). It is established that hyperglycaemia can occur in neurological disease and that hypoglycaemia may cause neurological disease (Ingram, Stark, and Blackburn, 1967; Neligan, 1969). The role of neurological disease in causing hypoglycaemia is more controversial (Cornblath and Schwartz, 1966; Wilson, 1968). In the present series hypoglycaemia often appeared multifactorial. In four of the cases (cases $6,33,58,64$ ) hypoglycaemia was felt to be secondary to neurological disease (see Appendix).

There appear to be two types of hyponatraemia which may complicate diseases of the brain (Nyhan and Cooke, 1956; Mangos and Lobeck, 1964). The first is manifest as a reduction of the total body sodium and fluid volume so that the patient is clinically dehydrated. The more common type found in neurological disease is associated with hyponatraemia with normal hydration or even oedema. This is most often due to water intoxication and may be due to inappropriate secretion of antidiuretic hormone. In the unconscious child the latter type may also be due to overtransfusion with hypo-osmolar fluids. The need for care in maintaining the fluid and electrolyte balance in unconscious patients can hardly be overestimated, for hyponatraemia or hypernatraemia may cause further neurological damage. Attempts to control hyperosmolar dehydration too rapidly-for example, in hypernatraemia-may result in brain swelling and oedema with decerebration, and this was responsible for the syndrome in three patients. Another condition which must be borne in mind in any acute neurological illness associated with disorders of fluid electrolyte balance is diabetes insipidus. Unsuspected diabetes insipidus may present with hypernatraemic dehydration and be the cause of brain damage.

In the management of a child showing decerebrate rigidity, the first aim must be to obtain an accurate diagnosis of the cause of his neurological abnormality. Prompt treatment of the underlying cause is essential as, for example, in the case of acute bacterial meningitis. In addition systemic treatment of any brain swelling, whatsoever the cause, must be early and energetic. Whenever raised pressure within the skull is suspected, the patient should be sat up in order to lessen intracranial venous pressure. Hydrocephalus should be relieved by tapping of the lateral ventricle when the fontanelle is open. The 
use of osmotic diuretics, steroid drugs, controlled hyperventilation, hypothermia, and hypotension has been reviewed recently by Shenkin (1970). Complicating convulsions may be treated by injecting diazepam with phenytoin intravenously. Disordered activity of homeostatic mechanisms may greatly aggravate the underlying neurological disease and cause death. The pulse rate, temperature, respiration, blood glucose, osmolality of the blood, acid base status, serum electrolytes, and urinary output must all be monitored and any abnormality corrected at an early stage. Neurosurgical consultation should be sought so that any amenable intracranial lesions can be treated early and effectively.

The appearance of decerebrate rigidity is always a serious sign, but with early and appropriate treatment the prognosis is less grave than formerly. Of 64 patients in the present series, $31 \%$ died and $36 \%$ of the 44 survivors had significant severe handicap. Forty per cent, however, of the total number of children had either no handicap or only a mild to moderate one. Some authors have suggested that the prognosis for patients showing decerebrate rigidity is better in childhood than adults, even after severe traumatic head injury. A mortality of $86 \%$ was found in a group of adults studied by Pia (1957). Since the criteria used in the selection of the present series were different from the criteria used in other series, direct comparisons cannot be made with the findings of Robertson and Pollard (1955), Brendler and Selverstone (1970), Gutterman and Shenkin (1970). The mortality for children showing decerebration will depend very greatly upon the causes of the syndrome and the treatment they are given.

We are grateful to Professor J. O. Forfar and the consultant paediatricians at the Royal Hospital for Sick Children, Edinburgh, and the Simpson Memorial Maternity Pavilion for ready access to patients admitted under their care, and to Professor J. O. Forfar for the care with which he read and suggested modifications to the manuscript. We are also grateful to Dr. A. Baine who performed the post mortem examinations and Mr. George Pollock for his interest and support in the investigation of handicapping conditions in childhood.

\section{REFERENCES}

Appenzeller, O. (1970). The Autonomic Nervous System. North Holland: Amsterdam
Brain, Lord, and Walton, J. N. (1969). Brain's Diseases of the Nervous System. 7th Edition. Oxford University Press: London.

Brendler, S. J., and Selverstone, B. (1970). Recovery from decerebration. Brain, 93, 381-392.

Brown, J. K. (1970). Neurological and EEG findings in infants with disordered calcium and magnesium metabolism. (Abstract.) Archives of Disease in Childhood, 45, 273274.

Buchanan, K. D. (1969). Hormonal control of carbohydrate metabolism. Journal of Clinical Pathology, 22, Suppl. 2, 2-6.

Chapman, W. P., Livingston, R. B., Livingston, K. E., and Sweet, W. H. (1950). Possible cortical areas involved in arterial hypertension. Research Publications of the Association for Research in Nervous and Mental Disease, 29, 775798.

Conomy, J. P., and Swash, M. (1968). Reversible decerebrate and decorticate postures in hepatic coma. New England Journal of Medicine, 278, 876-879.

Cornblath, M., and Schwartz, R. (1966). Disorders of Carbohydrate Metabolism in Infancy, pp. 229-230. Saunders: Philadelphia.

Denny-Brown, D. (1962). The midbrain and motor integration. Proceedings of the Roval Society of Medicine, 55, 527538.

Denny-Brown, D. (1962). The Basal Ganglia and Their Relation to Disorders of Movement, pp. 92-104. Oxford University Press: London.

Denny-Brown, D. (1963). The premotor syndrome in relation to extrapyramidâl symptoms. International Journal off Neurology, 4, 21-38.

Denny-Brown, D. (1966). The Cerebral Control of Movemen pp. 84-99. The Sherrington Lectures 8. Liverpool Uni@ versity Press: Liverpool.

Ducker, T. B. (1968). Increased intracranial pressure and pulmonary oedema. Part 1: clinical study of 11 patients. Journal of Neurosurgery, 28, 112-117.

Eastham, R. D., and Jancar, J. (1968). Clinical Pathology Mental Retardation, pp. 269-275. John Wright: Bristol.

Emery, J. L., and Reid, D. A. C. (1962). Cerebral oedema anis spastic hemiplegia following minor burns in young children. British Journal of Surgery, 50, 53-56.

Fulton, J. F. (1943). Physiology of the Nervous System, pp. 157-265. 2nd Edition. Oxford University Press: New York.

Granit, R. (1955). Receptors and Sensory Perception, pp. 273-275. Yale University Press: New Haven.

Gray, O. P., and Prosser, R. (1967). Heart failure with brain damage in the newborn. British Heart Journal, 29, 30-33.

Greer, M. (1967). Benign intracranial hypertension (pseudotumor cerebri). Pediatric Clinics of North America, 14, 819-830.

Gutterman, P., and Shenkin, H. A. (1970). Prognostic features in recovery from traumatic decerebration. Journal of Neurosurgery, 32, 330-335.

Halsey, J. H., and Downie, A. W. (1966). Decerebrate rigidity with preservation of consciousness. Journal of Neurology, Neurosurgery, and Psychiatry, 29, 350-355.

Hilton, S. M. (1966). Hypothalamic regulation of the cardiovascular system. British Medical Bulletin, 22, 243-248.

Ingram, T. T. S. (1964). Paediatric Aspects of Cerebral Palsy, pp. 210-216. Livingstone: Edinburgh.

Ingram, T. T. S., Stark, G. D., and Blackburn, I. (1967). 응 Ataxia and other neurological disorders as sequels of $D$ severe hypoglycaemia in childhood. Brain, 90, 851-862.

Ingram, T. T. S. (1970). The development of behaviour. In Child Life and Health, pp. 209-247. Edited by R. G. N Mitchell. 5th Edn. Churchill: London.

Johnson, R T., and Yates, P. O. (1956). Clinico-pathological N aspects of pressure changes at the tentorium. Acta Radiologica, 46, 242-249. 
Levine, R., and Haft, D. E. (1970). Carbohydrate homeostasis. New England Journal of Medicine, 283, 237-246.

McNealy, D. E., and Plum, F. (1962). Brainstem dysfunction with supratentorial mass lesions. Archives of Neurology, 7, 10-32.

Mangos, J. A., and Lobeck, C. C. (1964). Studies of sustained hyponatremia due to central nervous system infection. Pediatrics, 34, 503-510.

Martin, J. K., and Norman, R. M. (1967). Maple syrup urine disease in an infant with microgyria. Developmental Medicine and Child Neurology, 9, 152-159.

Morley, A. R. (1969). Laryngeal stridor, Arnold-Chiari malformation and medullary haemorrhages. Developmental Medicine and Child Neurology, 11, 471-474.

Morris-Jones, P. H., Houston, I. B., and Evans, R. C. (1967). Prognosis of the neurological complications of acute hypernatraemia. Lancet, 2, 1385-1389.

Neligan, G. (1969). Hypoglycaemia in infancy and childhood. Journal of Clinical Pathology, 22, Suppl. 2, 51-56.

Nyhan, W. L., and Cooke, R. E. (1956). Symptomatic hyponatremia in acute infections of the central nervous system. Pediatrics, 18, 604-613.

Paine, R., Smith, J. R., and Howard, F. A. (1952). Pulmonary oedema in patients dying with disease of the central nervous system. Journal of the American Medical Association, 149, 643-646.

Peiper, A. (1964). Cerebral Function in Infancy and Childhood. Translated from the 3rd German Edition by B. Nagler and H. Nagler. Pitman: London.

Pia, H. W. (1957). Die Schädigung des Hirnstammes bei den Raumfordernden Prozessen des Gehirns. Acta Neurochirurgica, Supplement 4.

Plum, F., and Swanson, A. G. (1959). Central neurogenic hyperventilation in man. Archives of Neurology and Psychiatry, 81, 535-549.

Posner, J. B., Swanson, A. G., and Plum, F. (1965). Acidbase balance in cerebrospinal fluid. Archives of Neurology, 12, 479-496.

Prechtl, H., and Beintema, D. (1964). The Neurological Examination of the Full-term Newborn Infant. Little Club
Clinics in Developmental Medicine, No. 12. Heinemann: London.

Reye, R. D. K., Morgan, G., and Baral, J. (1963). Encephalopathy and fatty degeneration of the viscera. A disease entity in childhood. Lancet, 2, 749-752.

Robertson, R. C. L., and Pollard, C., Jr. (1955). Decerebrate state in children and adolescents. Journal of Neurosurgery, 12, 13-17.

Roddie, I. C. (1969). Modern views on physiology. 7. Temperature control. Practitioner, 203, 108-114.

Rushworth, G. (1964). The nature and management of spasticity. Proceedings of the Royal Society of Medicine, 57, 715-720.

Shenkin, H. A., and Bouzarth, W. F. (1970). Clinical methods of reducing intracranial pressure. New England Journal of Medicine, 282, 1465-1471.

Sherrington, C. S. (1898). Decerebrate rigidity and reflex coordination of movements. Journal of Physiology, 22, 319332 .

Sherrington, C. S. (1906, 1947). The Integrative Action of the Nervous System. Yale University Press: New Haven.

Shuster, S. (1960). The electrocardiogram in subarachnoid haemorrhage. British Heart Journal, 22, 316-320.

Simpson, H. (1966). Encephalopathy and fatty degeneration of the viscera. Lancet, 2, 1274-1277.

Srivastava, S. C., and Robson, A. O. (1964). Electrocardiographic abnormalities associated with subarachnoid haemorrhage. Lancet, 2, 431-433.

Walshe, F. M. R. (1923). The decerebrate rigidity of Sherrington in man. Archives of Neurology and Psychiatry, 10, 1-28.

Walshe, F. M. R. (1923). A case of complete decerebrate rigidity in man. Lancet, 2, 644-647.

Wilson, J. (1968). Ataxia in childhood. Developmental Medicine and Child Neurology, 10, 388-390.

Wilson, S. A. K. (1920). On decerebrate rigidity in man and the occurrence of tonic fits. Brain, 43, 220-268.

Wylie, W. D., and Churchill-Davidson, H. C. (1966). $A$ Practice of Anaesthesia, pp. 248-250. Lloyd Luke: London.

Young, E., and Bradley, R. F. (1967). Cerebral oedema with irreversible coma in severe diabetic ketoacidosis. New England Journal of Medicine, 276, 665-669. 
APPENDIX TABLE

CLINICAL DETAILS OF 64 PATIENTS

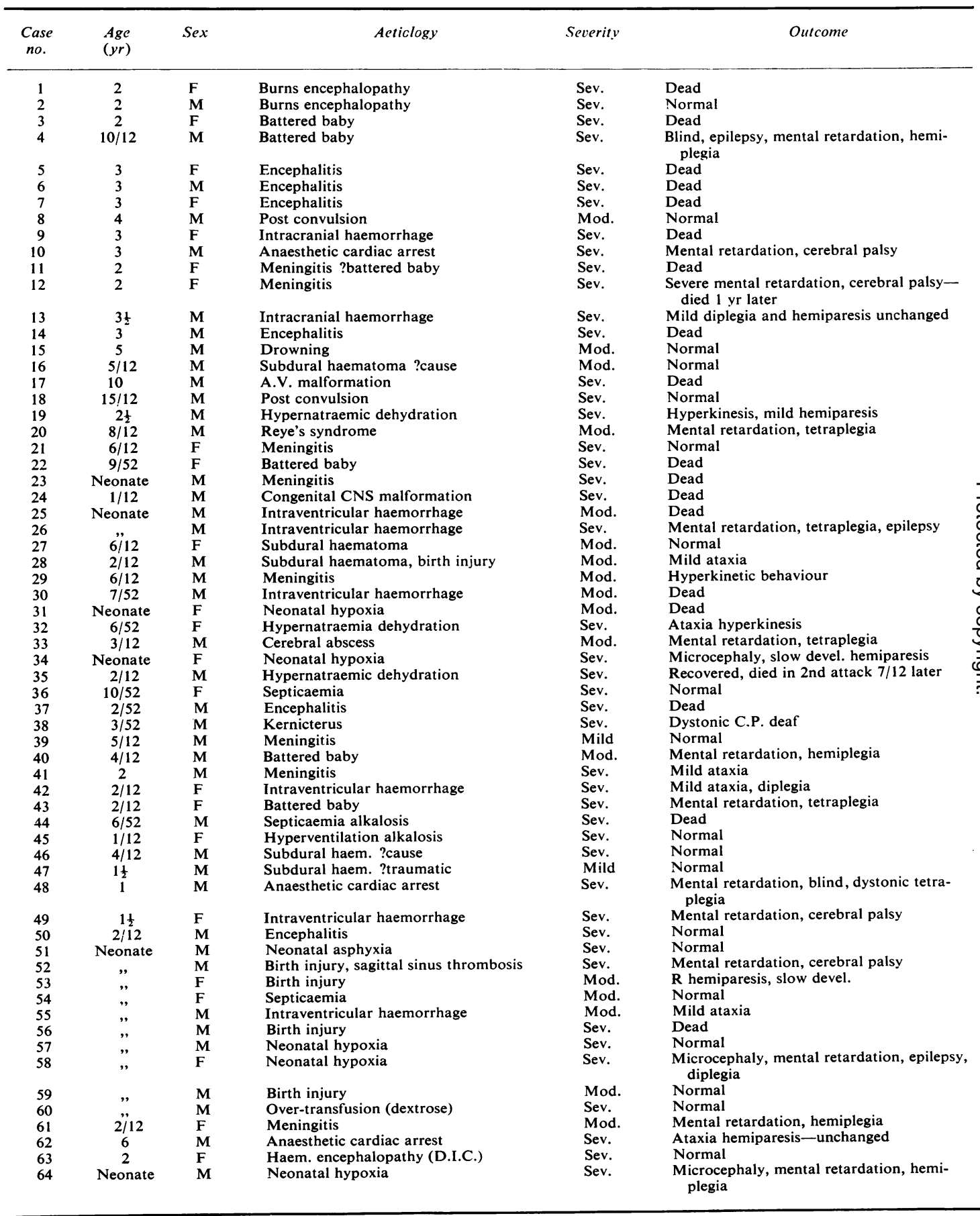

